\title{
Portal Hypertension: 2 years Experience in Department of Pediatric Gastroenterology and Nutrition, at a Tertiary Care Hospital, Bangladesh
}

\author{
Hussain $\mathrm{F}^{1}$, Karim $\mathrm{ASMB}^{2}$, Matin $\mathrm{MA}^{3}$, Sultana $\mathrm{K}^{4}$, Anwar $\mathrm{SA}^{5}$
}

\begin{abstract}
Background: Portal hypertension is a clinical syndrome defined by a pathologic increase of portal venous pressure. The objectives of this study were to evaluate etiological and clinical presentation of portal hypertension admitted in a tertiary care centre of Bangladesh. Materials and Methods: This cross sectional study was done at the Department of Paediatric Gastroenterology \& Nutrition, BSMMU on 100 consecutive cases admitted during the period from July 2013 through June 2015. Confirmation of the presence of portal hypertension was done by demonstration of oesophageal varices during upper GI endoscopic examination. The diagnosis of chronic liver disease was based on a combination of clinical, biochemical (abnormal liver function tests) and ultrasonographic (coarse echotexture of liver) features. Extrahepatic portal hypertension was diagnosed on the basis of clinical, normal liver function test and ultrasonographic evidence of portal or splenic vein thrombosis, with or without cavernous transformation. Doppler ultrasound showed increase portal venous pressure. Results: Patient's age group was 2 to 15 years. 69 cases were extra hepatic portal hypertension. Haematemesis and/or melaena were found in $42(60.9 \%)$ and splenomegaly was found in $68(98.6 \%)$ cases. Of extra hepatic 69 cases $10 \%$ had history of umbilical sepsis. Of the 31cases of CLD with portal hypertension, haematemesis and/or melaena was found in 20(64.5\%) cases, splenomegaly in $30(96.8 \%)$, ascites $8(25.8 \%)$.Most (50\%) of CLD cases were cryptogenic followed by Wilson's disease 29\%. Of the 100 cases, endoscopy revealed grade 3 esophageal varices in $45 \%$ cases. All the patients were treated with propranolol. EVL was done in $70 \%$ cases. Conclusion: In this study, most of the cases were extra hepatic portal hypertension. Gastrointestinal bleeding \& splenomegaly were found in most of the cases. No risk factor was found in most of extra hepatic cases. Portal vein thrombosis \& cryptogenic were the most common cause in extra-hepatic and intra-hepatic cases respectively. [J Shaheed Suhrawardy Med Coll 2016;8(1): 26-29]
\end{abstract}

Keywords: Portal Hypertension, Bangladesh.

\section{Introduction}

Portal hypertension (PH) is a common clinical syndrome defined as the elevation of hepatic venous pressure gradient (HVPG) above $5 \mathrm{~mm} \mathrm{Hg}$. PH is caused by a combination of two simultaneously occurring hemodynamic processes: (1) increased intrahepatic resistance to passage of blood flow through the liver due to cirrhosis and (2) increased splanchnic blood flow secondary to vasodilatation within the splanchnic vascular bed. PH can be due to many different causes at prehepatic, intrahepatic and posthepatic sites ${ }^{1}$. However, when PH develops, the portal pressure is higher than that of systemic venous pressure, and this leads to reversal of flow in the collaterals ${ }^{1}$. PH is considered to be clinically significant when HVPG exceeds 10 to $12 \mathrm{~mm} \mathrm{Hg}$, since this is the threshold for the clinical complications of PH to appear².

Portal hypertension can be hepatic or extrahepatic. Portal hypertension presents with GI bleeding, splenomegaly and in hepatic cases with features or complications of chronic liver disease.

Esophageal varices (EV): EV form when the HVPG exceeds $10 \mathrm{mmHg}^{3}$. EV are graded as small $(<5 \mathrm{~mm})$ and large $(>5 \mathrm{~mm})$. The rate of progression of small EV to large is $8 \%$ per year ${ }^{4}$. The predictors of first bleeding include the size of varices, severity of cirrhosis (Child B or C), variceal pressure $(>12 \mathrm{mmHg})$, and the endoscopic presence of red wale marks $^{5,6}$.

\footnotetext{
1. Faika Hussain, Registrar, Department of Paediatrics, Shaheed Suhrawardy Medical College Hospital.

2. A S M Bazlul Karim, Chairman, Department of Paediatric Gastroenterology, BSMMU.

3. Abdul Matin, Associate Professor, Department of Paediatrics, Shaheed Suhrawardy Medical College Hospital.

4. Kaniz Sultana, Outdoor Medical Officer Eye, Dhaka Medical College Hospital.

5. Syeda Afria Anwar, Consultant, Gastroliver Hospital.

\section{Correspondence}

Dr Faika Hussain, Registrar, Department of Paediatrics, Shaheed Suhrawardy Medical College Hospital, Dhaka. E-mail: hussainfaika@gmail.com; cell no: +8801819262896
} 
Gastroesophageal varices (GOV): GOV are an extension of $\mathrm{EV}$. GV are less common than EV and are present in $5 \%-30 \%$ of patients with $\mathrm{PH}^{7}$.

Use of propranolol (1-2mg/kg body weight/day). Children with varices are to be initiated, but follow up endoscopy is to be done to check the status every 6-12 month interval. Prophylactic endoscopic sclerotherapy and variceal obliteration is also in practice ${ }^{8}$.

For treatment of acute bleeding several drugs (vasopressin, terlipressin, somatostatin \& octreotide) are also used as well as endotherapy, balloon tamponade. Transjugular intrahepatic portosystemic shunts (TIPS) are done for uncontrolled variceal bleeding.

Esophageal variceal bleeding is one of the most important complications of both cirrhotic and non cirrhotic portal hypertension because of its high mortality.

Increasing in size of varices is associated with an increase in variceal wall tension to a critical level at which varices rapture and cause life threatening bleeding. Mortality of variceal bleeding is $30-50 \%$ within the first week of a bleeding episode. Thus variceal bleeding prevention is an important factor for the patient as well as for the physician dealing with them and the first step of this prevention is to identify the patient at risk of bleeding. Complication can be prevented by endotherapy and prophylactic treatment with beta adrenergic receptor antagonists. Thus it can reduce the incidence of variceal bleeding.

Several studies are there in adult group which demonstrated etiology and clinical presentation of portal hypertension. But in paediatric age group there are limited studies in our country. So this study is aimed to evaluate etiological and clinical presentation of portal hypertension admitted in a tertiary care centre of Bangladesh. Thus it will help to initiate early prophylactic treatment to prevent catastrophic event and reduce morbidity and mortality.

\section{Materials and Methods}

This cross sectional study was done at the Department of Paediatric Gastroenterology \& Nutrition, Bangabandhu Sheikh Mujib Medical University (BSMMU) on 100 consecutive cases admitted during the period from July 2013 through June 2015. Patients aged 2- 15 years, presents with GI bleeding,with or without splenomegaly are included. Confirmation of the presence of portal hypertension was done by demonstration of oesophageal varices during upper GI endoscopic examination. The diagnosis of chronic liver disease (CLD) was based on a combination of clinical, biochemical (abnormal liver function tests) and ultrasonographic (coarse echotexture of liver) features. Extrahepatic portal hypertension was diagnosed on the basis of clinical, normal liver function test (LFT) and ultrasonographic evidence of portal or splenic vein thrombosis, with or without cavernous transformation. Doppler ultrasound was done in extrahepatic group on the basis of availability and affordability which showed increase portal venous pressure. Their clinical history regarding neonatal sepsis or catheterization, dehydration, history of parentral exposure to infected (Hepatitis B) blood or fluid, examination findings \& initial investigation reports were recorded in a standard data sheet by the researcher herself. Complete blood count was done in all patients to estimate hemoglobin and platelet count before endoscopy. To find out the cause of chronic liver disease HBsAg, Anti HCV(total), S. Ceruloplasmin, 24 hours urinary copper(after giving 500 mg Cap Penicillamine 12 hours apart), IgA anti- tTG (tissue transglutaminase), auto immune marker, fasting blood glucose, lipid profile, sweat chloride was done.

During recruitment, objectives of the study were explained to the parents or guardians \& written consent were obtained. Statistical analysis was done using Statistical Package of Social Science (SPSS) version 17.

\section{Results:}

Patient's age group was 2 to 15 years. Male female ratio was 4:1. 69 cases were extra hepatic portal hypertension. Haematemesis and/or melaena were found in $42(60.9 \%)$ and splenomegaly was found in $68(98.6 \%)$ cases. Most of the patients were found anaemic $(94.2 \%)$. Of extra hepatic 69 cases $10 \%$ had history of umbilical sepsis, 5.8\% dehydration and others were idiopathic. Of the 31 cases of CLD with portal hypertension, haematemesis and/or melaena was found in 20(64.5\%) cases, anaemia 24(77.4), jaundice 21(67.7\%), oedema 11(35.5\%), splenomegaly $30(96.8 \%)$, hepatomegaly $7(22.6)$ and ascites in $8(25.8 \%)$. Most $(50 \%)$ of CLD cases were cryptogenic followed by Wilson's disease 29\%, HBV $8 \%$ and others $13 \%$. Of the 100 cases, endoscopy revealed grade 3 esophageal varices in $45 \%$ cases. All the patients were treated with propranolol. EVL was done in $70 \%$ cases.

Table 1: Age and sex distribution of the studied patients $(n=100)$

\begin{tabular}{lccc}
\hline Age & Male & Female & Total \\
\hline$\leq 5$ & 12 & 1 & 13 \\
$6-10$ & 38 & 10 & 48 \\
$11-15$ & 30 & 9 & 39 \\
\hline
\end{tabular}

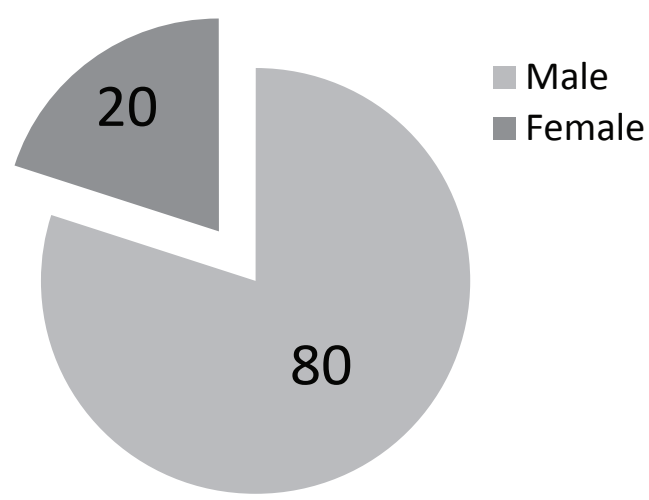

Figure 1: Pie chart showing sex distribution of the studied patients $(n=100)$ 
Table 2: Clinical findings of patients with Portal Hypertension( $\mathbf{n}=100)$

Most of the patients in both group had a history of hematemesis \&/or melaena. On examination anaemia and splenomegaly were the commonest findings. Of extra hepatic 69 cases $58(84.1 \%)$ were idiopathic.

\begin{tabular}{lcc}
\hline Clinical findings & $\begin{array}{c}\text { Extra hepatic(n=69) } \\
\text { No. (\%) }\end{array}$ & $\begin{array}{c}\text { Hepatic(n=31) } \\
\text { No. (\%) }\end{array}$ \\
\hline History: & & \\
Hematemesis \&/or Melaena & $42(60.9)$ & $20(64.5)$ \\
Idiopathic & $58(84.1)$ & \\
Neonatal sepsis & $7(10.1)$ & \\
Dehydration & $4(5.8)$ & \\
Examination: & & \\
Anaemia & $65(94.2)$ & $24(77.4)$ \\
Jaundice & $21(67.7)$ & \\
Pedal oedema & $11(35.5)$ & \\
Splenomegaly & $68(98.6)$ & $30(96.8)$ \\
Hepatomegaly & $7(22.6)$ & \\
Ascites & $8(25.8)$ & \\
\hline
\end{tabular}

Table 3: Investigation findings of studied children $(n=100)$

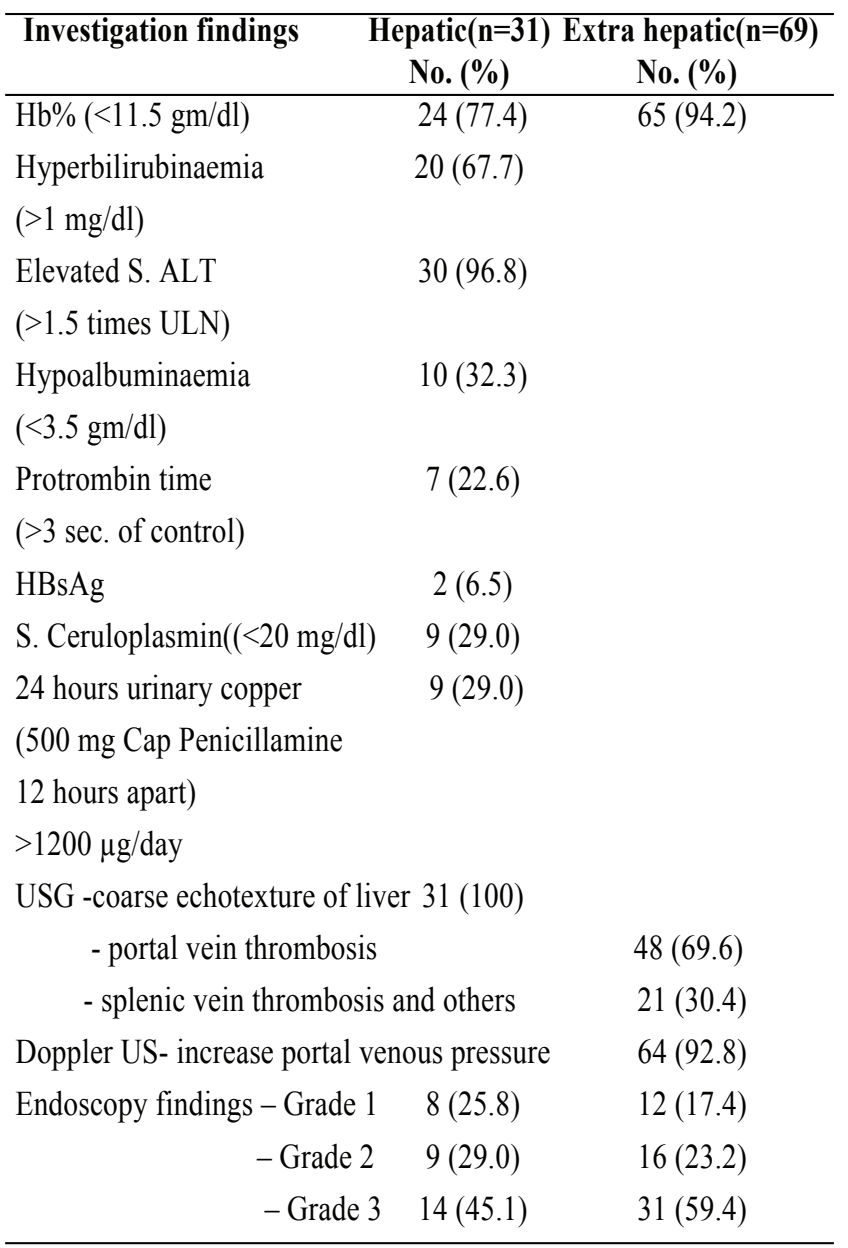

Some patients had more than one laboratory findings. ULN - Upper limit of normal,

$$
\text { USG - Ultrasonogram }
$$

Doppler ultrasound was done in extrahepatic group. It couid not be done in 5 cases due to unaffordability.

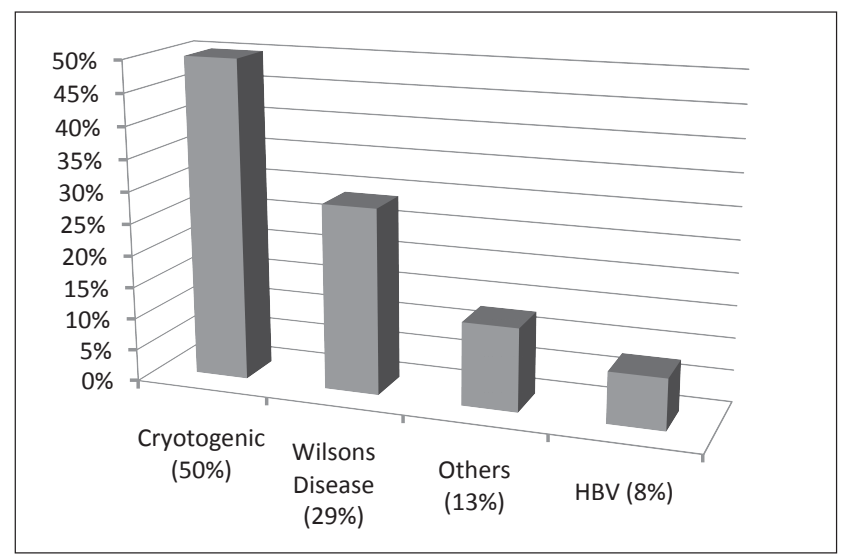

Figure 1: Etiology of CLD with portal hypertension $(\mathrm{n}=31)$

(Others- Celiac disease-1, cystic fibrosis-1, Biliary atresia-1, Glycogen storage disease-1)

\section{Discussion}

This study was carried out in Paediatric Gastroenterology \& Nutrition department of BSMMU. Patients aged 2-15 years, presents with GI bleeding, with or without splenomegaly are included. Mean age was $9.2 \pm 5.8$ years among studied children. Similar result was also observed in a study in Iran. Their mean age was $7.6 \pm 4.7^{9}$.

In the present study male:female ratio was $4: 1$. So, portal hypertension more observed in male than female. But Imanieh et $\mathrm{al}^{9}$ reported the different result. There ratio was $1.01: 1$. This is may be due to under reporting of symptoms in female patient in our country.

Splenomegaly found in most of the cases in patients with portal hypertension in this study. Sharma and Aggarwal ${ }^{10}$ also found splenomegaly as independent predictors of large esophageal varices.

Confirmation of the presence of portal hypertension was done by demonstration of oesophageal varices during upper GI endoscopic examination. Extrahepatic portal hypertension was diagnosed on the basis of history (umbilical sepsis in 10\%, dehydration 5.8\% and idiopathic in others), normal LFT, USG findings that is portal vein thrombosis in $69.6 \%$ and splenic vein thrombosis in others. Doppler US- showed increase portal venous pressure in 64 out of extra hepatic 69 cases.

Arora et $\mathrm{al}^{11}$ observed that $76.5 \%$ cases of extra-hepatic portal hypertension in North Indian children. This study revealed the similar result. $69 \%$ were extra hepatic portal hypertension. However, controversy exists regarding the suggested patterns of portal hypertension in children and adults, and it appears that this pattern is regionally variable. In some studies performed in the West, intrahepatic portal hypertension was more frequent in children $^{4}$, whereas studies performed in India observed that extra-hepatic portal hypertension was more frequent in children ${ }^{12}$.

In the present study, among all children with extra-hepatic portal venous obstruction, portal vein 
thrombosis was the leading cause. Out of 69 children, it was observed in $48(69.6 \%)$ cases. Podder et al. $^{7}$ and Arora et al. ${ }^{11}$ also reported similar results.

The diagnosis of CLD was based on abnormal LFT which showed hyperbilirubinaemia

in

$20(67.7 \%)$ cases, elevated S. ALT in $30(96.8 \%)$, hypoalbuminaemia in $10 \quad(32.3 \%)$ and raised protrombin time in $7(22.6 \%)$ cases.

Imanieh et $\mathrm{al}^{9}$ reported that, main cause of intrahepatic portal hypertension was cryptogenic. Out of 45 children, it was observed in $12(26.7 \%)$ cases. Other causes were biliary cirrhosis $11(24.4 \%)$ cases and Wilson's disease 8 $(17.8 \%)$ cases. Similar results were observed in our study. Out of 31 children, cryptogenic were $50 \%$ cases followed by Wilson's disease in $29 \%$ cases.

\section{Conclusion}

In this study, most of the cases were extra hepatic portal hypertension. Gastrointestinal bleeding \& splenomegaly were found in most of the cases. No risk factor was found in most of extra hepatic cases. Portal vein thrombosis \& cryptogenic were the most common cause in extra-hepatic and intra-hepatic cases respectively.

\section{References}

1. Al-Busafi, S.A., McNabb-Baltar, J., Farag, A. (2012). Clinical Manifestations of Portal Hypertension. International Journal of Hepatology, 1-10.

2. Groszmann, R.J., Garcia-Tsao, G., Bosch, J., Grace, N.D., Andrew, K., Planas, R., Matloff, D. et al. (2005). Beta-Blockers to Prevent Gastroesophageal Varices in Patients with Cirrhosis. New England Journal of Medicine, 353 (21), 2254-2261.
3. Geraci, G., Arnone, E., Lo Nigro, C., Sciuto, A., Modica, G., Sciume, C. (2011). Endoscopic rubber band ligation in treatment of esophageal varices bleeding. Personal experiences. G Chir, 32 (3), 113-117.

4. Maksoud, JG., Goncalves, MEP., Porta, G., Miura, I., Velhote, MCP. (1991). The endoscopic and surgical management of portal hypertension in children: analysis of 123 cases. J Pediatr Surg, 26, 178-81.

5. Brocchi, E., Caletti, G., Brambilla, G., et al. (1988). Prediction of the first variceal hemorrhage in patients with cirrhosis of the liver and esophageal varices: A prospective multicenter study. New England Journal of Medicine, 319 (15), 983-989.

6. Merli, M., Nicolini, G., Angeloni, S., Gentili, F., Attili, A.F., Riggio, O. (2004). The natural history of portal hypertensive gastropathy in patients with liver cirrhosis and mild portal Hypertension. Am J Gastroenterol, 99, 1959-6.

7. Ozsoylu, S., Kocak, N., Demir, H., Yuce, A., Gurakan, F., Ozen, H. (2000). Propanolol for primary and secondary prophylaxis of variceal bleeding in children with cirrhosis. Turk J Pediatr, 42, 31-33.

8. Nevens, F., Bustami, R., Scheys, I., Lesaffre, E., Fevery, J. (1998). Variceal pressure is a factor predicting the risk of a first variceal bleeding: a prospective cohort study in cirrhotic patients. Hepatology, 27 (10), 15-19.

9. Imanieh MH, Dehghani SM, Khoshkhui M, Malekpour A. Etiology of portal hypertension in children: A single center's experiences. (2012). Middle East J Dig Dis, 04, 206-10.

10. Poddar, U., Thapa, BR., Rao, KLN., Singh, K. (2008). Etiological spectrum of esophageal varices due to portal hypertension in Indian children: Is it different from the West? J Gastroenterol Hepatol, 23, 1354-7.

11. Arora, NK., Lodha, R., Gulati, S., Gupta, AK., Mathur, P., Joshi, MS et al. (1988). Portal hypertension in North Indian children. Indian Pediatr, 65: 585-91.

12. Yachha, SK. Portal hypertension in children: an Indian perspective. (2002). J Gastroenterol Hepatol. 17( 3), 228-31. 